\title{
NOTA DE LA DIRECCIÓN
}

La revista Historia Contemporánea comenzó su andadura en 1988, por lo tanto este año 2018 cumple 30 años de existencia. A lo largo de este periodo, hemos realizado diversos cambios al hilo de la profunda transformación que ha experimentado el mundo de las publicaciones científicas en España. Ahora, coincidiendo con este aniversario añadimos varias novedades.

Primera, el cambio en la dirección. Tras los primeros años fundacionales dirigida por Manuel Tuñón de Lara (1988-1996), durante los últimos veinte años, entre 1997 y 2017, ha sido Manuel González Portilla quien ha estado al frente de la revista. En este momento deja la responsabilidad en manos del equipo directivo actual. Concretamente, José María Beascoechea ocupará el puesto de director y Eduardo J. Alonso Olea el de editor.

En segundo lugar, con el fin de atender a la creciente demanda de la comunidad académica, desde este 2018 adoptamos una periodicidad cuatrimestral, con tres números anuales: febrero, junio y octubre. Asimismo, pretendemos que este cambio agilice el proceso editorial y permita atender mejor a nuestros autores y lectores.

Finalmente, con este número la revista comienza a publicar un primer texto en inglés. Esperamos que se convierta en una práctica cada vez más habitual a partir de ahora. 